\title{
Escola de Tempo Integral: resultados do projeto na proficiência dos alunos do Ensino Fundamental das escolas públicas da rede estadual de Minas Gerais
}

\author{
Tufi Machado Soares* \\ Juliana de Lucena Ruas de Riani** \\ Mariana Calife Nóbrega*** \\ Neimar Fernandes da Silva ${ }^{* * *}$
}

\section{Resumo}

Neste trabalho avaliam-se os efeitos do Projeto Escola de Tempo Integral, desenvolvido pelo Governo do Estado de Minas Gerais desde o ano de 2007 nas escolas estaduais mineiras, nos resultados das avaliações em larga escala de Língua Portuguesa e Matemática. Nesse sentido, o projeto tem apresentado resultados positivos ao promover as proficiências dos alunos com defasagens de aprendizagem. O estudo observacional foi baseado nos resultados dos alunos de cerca de 1900 escolas que aderiram ao projeto entre 2006 e 2009, utilizando técnicas baseadas em escore de propensão e modelos multiníveis de regressão. Palavras-Chaves: Educação Básica. Avaliação de Políticas Educacionais. Escola de Tempo Integral. Modelo Multinível. Escore de Propensão.

\section{Introdução}

A ideia de uma educação integral para o homem não é recente na história humana. De uma maneira geral, a educação integral preconiza a formação mais completa possível do indivíduo dentro de uma rede complexa que envolve desde o aprendizado cognitivo ao cultural e social, emocional, artístico e corporal, crítico-emancipatório, entre outros, dependendo da corrente teórica, incluindo aí todas as suas relações,

* Professor da UFJF e Coordenador de Pesquisa do Centro de Políticas Públicas e Avaliação da Educação - CAEd. Av. Eugênio do Nascimento, 620 - B. Dom Orione - Juiz de Fora - MG CEP: 36038-330; tufi@caed.ufjf.br.

** Secretaria de Educação de Minas Gerais.

*** Mestre em Educação pela UFJF. Pesquisadora do Centro de Políticas Públicas e Avaliação da Educação - CAEd.

**** Pesquisador do Centro de Políticas Públicas e Avaliação da Educação - CAEd. 
para a plena formação do cidadão. Apesar de essas concepções teóricas dependerem da vertente política à qual se aderem, a ideia de uma educação integral é comum às diversas propostas de organização social (COELHO, 2009). Portanto, existe uma grande literatura sobre o tema, que o aborda sobre os mais diversos enfoques. No entanto, não é objetivo deste trabalho discutir esses enfoques e seus desdobramentos. O fato é que como quase todas as correntes de pensamento no Brasil atribuem ao estado e, por meio dele, à escola pública a tarefa de uma formação integral do indivíduo, naturalmente, impõe-se a necessidade de adequar o espaço, o tempo e os meios necessários para que ela cumpra o seu papel. A ampliação da jornada escolar é o primeiro passo nessa direção e surge como uma necessidade, quer seja pela ambição de uma educação que contemple tantos objetivos, quer pela constatação de que as desigualdades sociais no Brasil demandam tratamentos diferenciados para os alunos oriundos das classes menos favorecidas.

Nesse sentido, Cavaliere acrescenta que a ampliação da jornada escolar fundamenta-se no fortalecimento e ênfase das escolas, como local central no processo de formar os alunos, redimensionando a estrutura escolar, equipandoas com profissionais e materiais que ajudam no exercício de novas atividades com o aluno. Essa vivência de experiências de ampliação da jornada de tempo na escola, a autora denominou como "escola de tempo integral".

(...) a ênfase estaria no fortalecimento da unidade escolar, com mudanças em seu interior pela atribuição de novas tarefas, mais equipamentos e profissionais com formação diversificada, pretendendo propiciar aos alunos e professores uma vivência institucional de outra ordem. (CAVALIERE, 2009, p. 53).

Os contextos que dirigem a ampliação, na perspectiva de escola de tempo integral, estão pautados a uma preocupação com progresso dos resultados escolares e na inquietação em oferecer aos alunos possibilidades diferenciadas de aprender o conteúdo escolar.

Entende-se que a avaliação na Escola de Tempo Integral não está a serviço da aprovação ou reprovação dos alunos, mas de um diagnóstico que auxilie a definição de encaminhamentos, visando à aprendizagem no curso regular, ou seja, articulada ao projeto político pedagógico da escola. É vista, portanto, como um processo formativo e contínuo. 
As diferentes propostas de escola em tempo integral, contudo, diferem muito pouco na prática e, em geral, têm procurado contemplar a ampliação das atividades curriculares, lazer e esporte, atividades culturais e artísticas e, ainda, exposição dos alunos a temas cotidianos e transversais, tais como direitos humanos, cidadania, meio ambiente, entre outros. Por outro lado, o reforço acadêmico, a alimentação e a saúde da criança tornam-se fundamentais nos modelos de ampliação da jornada escolar dado que as horas passadas na escola se ampliam, mas também porque as necessidades de grande parte dos alunos as impõem.

Anísio Teixeira, um dos intelectuais mais proeminentes da "Escola Nova", propunha um modelo de educação integral que, além de ser um programa completo de disciplinas tradicionalmente escolares, incluísse também atividades lúdicas e garantisse a saúde e o alimento à criança. Esse modelo foi colocado em prática no Centro Educacional Carneiro Ribeiro em Salvador, Bahia, na década de 1950. O pensamento de Anísio Teixeira influenciou substancialmente o modelo de escola de tempo integral implantado em Minas Gerais e objeto de estudo deste trabalho.

O Projeto Escola de Tempo Integral - nascido como uma das ações integrantes do projeto Escola Viva, Comunidade Ativa: o Aluno de Tempo Integral - da Secretaria de Educação do Estado de Minas Gerais objetiva, principalmente, elevar a qualidade do ensino, ampliar a área de conhecimento ao aluno e reduzir a possibilidade de reprovação, promovendo $o$ atendimento do aluno com defasagens de aprendizagem e promovendo atendimento integral ao discente em atividades artísticas, culturais e esportivas (SECRETARIA DE ESTADO DE EDUCAÇÃO DE MINAS GERAIS, 2009).

O modelo de Tempo Integral, implantado em 2005 nas escolas participantes do Projeto Escola Viva, Comunidade Ativa, foi expandido para escolas de toda a rede estadual de ensino dos municípios mineiros. No ano de 2010, segundo os dados da Secretaria de Estado de Educação de Minas Gerais (SEE/MG), o projeto beneficiou cerca de 106 mil alunos em 1790 escolas de 550 municípios mineiros. Ainda segundo as informações da Secretaria de Educação de Minas Gerais, a meta do Governo do Estado é de que o projeto seja implantado em todas as escolas mineiras para atender a todas as turmas de Ensino Fundamental.

Uma avaliação de um projeto dessa envergadura e com objetivos tão abrangentes envolve análises e estudos muito amplos e direcionados à eficácia dos diferentes objetivos, por meio de diferentes metodologias. O estudo que aqui se está 
apresentando contempla a eficácia do projeto no que se refere à melhoria das habilidades cognitivas dos alunos, o que, por si só, já representa um grande desafio metodológico e instrumental dada a concorrência de projetos existentes nos sistemas educacionais. Por outro lado, o modelo de estudo observacional (ex post) naturalmente se impõe, tendo em vista que não foi previsto originalmente qualquer estudo experimental para a avaliação do projeto.

\section{A Escola de Tempo Integral em Minas Gerais e o seu contexto histórico}

No estado de Minas Gerais, em 2003, foi implantado pela Secretaria de Estado de Educação, o Projeto Escola Viva, Comunidade Ativa, cujo objetivo era combater a violência nas escolas em áreas urbanas dos municípios mineiros. Em 2005, foi implantado pela mesma secretaria o Projeto Aluno de Tempo Integral. Como componente do Projeto Escola Viva, Comunidade Ativa, este projeto foi utilizado como estratégia encontrada para, gradativamente, tornar as escolas da rede estadual de ensino mineiro capazes de atender aos alunos em tempo integral de ensino.

Segundo os dados da Secretaria de Educação Mineira, em 2006 foram beneficiados cerca de 19,9 mil alunos do Ensino Fundamental de 171 escolas participantes do Projeto Escola Viva, Comunidade Ativa, em quatorze municípios da Capital e da Região Metropolitana, no turno contrário ao das aulas formais, no mesmo espaço da escola ou em outros espaços sociais, valendo-se de parcerias Em 2010, a ampliação do projeto fez parte das principais ações desenvolvidas pelo governo do Estado, pois foram cerca de 106.000 alunos atendidos em mais de 1.700 escolas de municípios do Estado de Minas Gerais.

No ano de 2008, ocorreu a separação entre os projetos. Dessa forma, o foco da Escola de Tempo Integral passou a ser a aprendizagem do aluno das escolas públicas mineiras, e não somente aquelas integrantes do Escola Viva, Comunidade Ativa.

De acordo com a secretaria de educação mineira, o projeto se apoia em algumas ideias das correntes liberais que pensavam a educação integral como vetor de reconstrução das bases sociais para o desenvolvimento democrático. Entre os liberais, destaca-se o nome de Anísio Teixeira, importante teórico que ressaltava a ampliação das funções da escola e o seu fortalecimento como instituição de ensino. 
A concepção de Anísio Teixeira - desenvolvida e aperfeiçoada - envolveu diversos elementos, entre eles a da permanente defesa do aumento da jornada escolar discente nos diferentes níveis de ensino. $\mathrm{O}$ autor apresentou sugestões para que a articulação das instâncias federal, estadual e municipal garantisse aos serviços educacionais a necessária unidade, transformando-os em uma das prioridades do serviço público do país (SEE/MG, 2009). Para tanto, concebeu o sistema nacional, o qual previa que as localidades a partir de dois mil habitantes deveriam receber uma escola de tempo integral. Na década de 1960, o sistema educacional brasileiro foi planificado a partir das ideias de Anísio. As bases sobre as quais o autor formula sua concepção de educação integral são, resumidamente, o entendimento de que educação é vida e não preparação para a vida, o entendimento de que as demais instituições sociais perderam parte de suas capacidades educativas e a busca da escola verdadeiramente comum, isto é, uma escola democrática.

O artigo 34 da Lei de Diretrizes e Bases da Educação Nacional / LDBEN pressupõe que: "A jornada escolar no Ensino Fundamental incluirá pelo menos 4 horas de trabalho efetivo em sala de aula, sendo progressivamente ampliado o período de permanência na escola”. Em conformidade com a LDB, a Secretaria Estadual de Educação de Minas Gerais elaborou orientações gerais e diretrizes metodológicas que subsidiaram as instituições escolares na elaboração e implantação do Projeto Escola de Tempo Integral em cada uma das instituições. Segundo a Secretaria Estadual de Educação, o objetivo implica a criação de oportunidades para que o aluno possa desenvolver-se como cidadão; para que a escola efetivamente lhe garanta melhor aprendizagem, no intuito de que ele possa progredir nos estudos, superando obstáculos e enfrentando desafios (SECRETARIA ESTADUAL DE EDUCAÇÃO DE MINAS GERAIS, 2009).

Dentre os objetivos específicos propostos pelo referido projeto, destacam-se: melhoria na aprendizagem dos alunos do Ensino Fundamental que demandem maior atenção do Sistema Educacional, ampliando a carga horária dos discentes; elevação da qualidade do ensino; ampliação da área do conhecimento do aluno, permitindo uma visão globalizada dos conteúdos curriculares trabalhados; promoção do atendimento ao aluno com defasagem de aprendizagem; redução da possibilidade de reprovação, tendo em vista que o aluno terá no "extraturno" atividades para o desenvolvimento de suas habilidades e competências e desenvolvimento das atividades artísticas, culturais e esportivas que ampliem o universo de experiências dos alunos. Sendo essa uma política educacional 
focalizada, são os alunos com baixo desempenho nos testes de proficiência das avaliações em larga escala que são selecionados pelos professores para participarem do projeto.

Segundo as orientações da cartilha ofertada às escolas e aos docentes envolvidos, a aprendizagem em tempo integral deve basear-se numa ação pedagógica organizada por projetos.

Nesta perspectiva, a ênfase do desenvolvimento integral será a partir de uma área ou tema do conhecimento como eixo para o desenvolvimento de outras competências. Neste caso, o trabalho, a arte, o esporte, o lazer, a sexualidade, o meio ambiente, a saúde, entre outros não são temas transversais, mas, ao contrário, constituem projetos que aglutinam conhecimentos e estabelecem conexão com outras necessidades dos sujeitos. Destaca-se, principalmente, uma metodologia participativa que envolve a vida prática comunitária, voltada para solução de questões que inquietam ou estimulam a vida cotidiana e que, por isso mesmo, exercem forte motivação e interesse.

Trata-se de considerar excursões, atividades extra-escola e aulas em sala de aula, como um todo, um projeto pedagógico de desenvolvimento de uma determinada disciplina, em que não precisa haver repetição e que a diversão não é inimiga da aprendizagem, ao contrário, quando aprendemos de modo prazeroso, esse aprendizado se torna muito mais significativo. Uma nova dinâmica foi proposta para as escolas. A Educação em Tempo Integral requer a mobilização de toda a comunidade escolar, especialmente dos professores, para um planejamento conjunto que assegure atendimento das necessidades educativas dos alunos e desenvolvimento das ações, com o máximo de aproveitamento das intervenções pedagógicas desde o diagnóstico até os conteúdos e atividades. O projeto procura atender as necessidades educativas dos alunos com dificuldades de aprendizagem nos conteúdos curriculares, bem como desenvolver atividades artísticas, culturais e esportivas que ampliem o universo de experiências dos mesmos. Esta delimitação do campo de ação facilita a concentração do trabalho pedagógico, permitindo uma avaliação mais clara dos resultados. (SECRETARIA DE ESTADO DE EDUCAÇÃO DE MINAS GERAIS, 2009). 
O currículo proposto pelo Projeto Escola de Tempo Integral pressupõe a flexibilidade da carga horária e das atividades trabalhadas. O tempo do aluno na escola deve ter novo formato, mais adaptado às necessidades do projeto:

esta nova dinâmica curricular, com maior flexibilidade, permite que a ação escolar tenha um caráter mais interdisciplinar, na medida em que favorece o trabalho coletivo e estimula a superação da fragmentação das disciplinas e dos conteúdos escolares convencionais (SECRETARIA DE ESTADO DE EDUCAÇÃO DE MINAS GERAIS, 2009).

A Matriz Curricular do Tempo Integral, conforme descrito no projeto, pressupõe a realização de oficinas curriculares na área de linguagem e matemática, na área artística, esportiva e motora e na área de formação pessoal e social. Dentro das disciplinas, a escola faz sua opção de oficinas, conforme interesse e necessidade dos alunos.

\section{A evolução das proficiências em Minas Gerais e a proposta de avaliação do Projeto Escola de Tempo Integral}

Após quase uma década de Avaliação em Larga Escala é possível observar um crescimento, e de forma consolidada, da qualidade do ensino expressa no aprendizado do aluno por meio dos resultados trazidos pelo PROEB ${ }^{1}$. Os gráficos de 1 a 4 apresentam o crescimento da proficiência média na rede estadual para $05^{\circ} \mathrm{e}$ $9^{\circ}$ ano nas disciplinas avaliadas - Língua Portuguesa e Matemática, de 2006 a 2009.

1 O PROEB - Programa de Avaliação da Educação básica de Minas de Gerais, é um componente do SIMAVE - Sistema Mineiro de Avaliação educacional, que foi introduzido em 2000 pela SEE de Minas Gerais. Basicamente, consiste na apliçção de testes cognitivos nos anos finais dos dois segmentos do Ensino Fundamental ( $5^{\circ}$ ano do $\mathrm{EF}$ e $9^{\circ}$ ano do EF) e no final do Ensino Médio, em toda rede estadual de educação e praticamente toda rede municipal. 
Gráfico 1 - Proficiência dos anos 2006 a 2009 em Matemática do 5ª ano da Rede Estadual

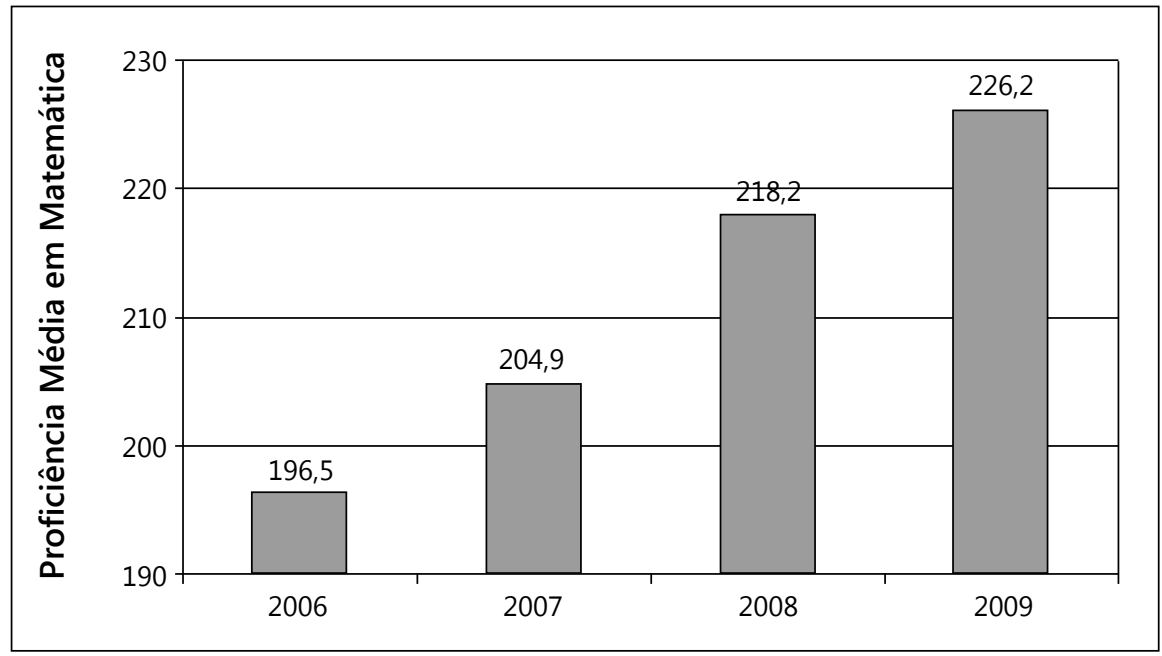

Fonte: SECRETARIA DE ESTADO DE EDUCAÇÃO DE MINAS GERAIS (2010).

Gráfico 2 - Proficiência dos anos 2006 a 2009 em Língua Portuguesa do 5ªno da Rede Estadual

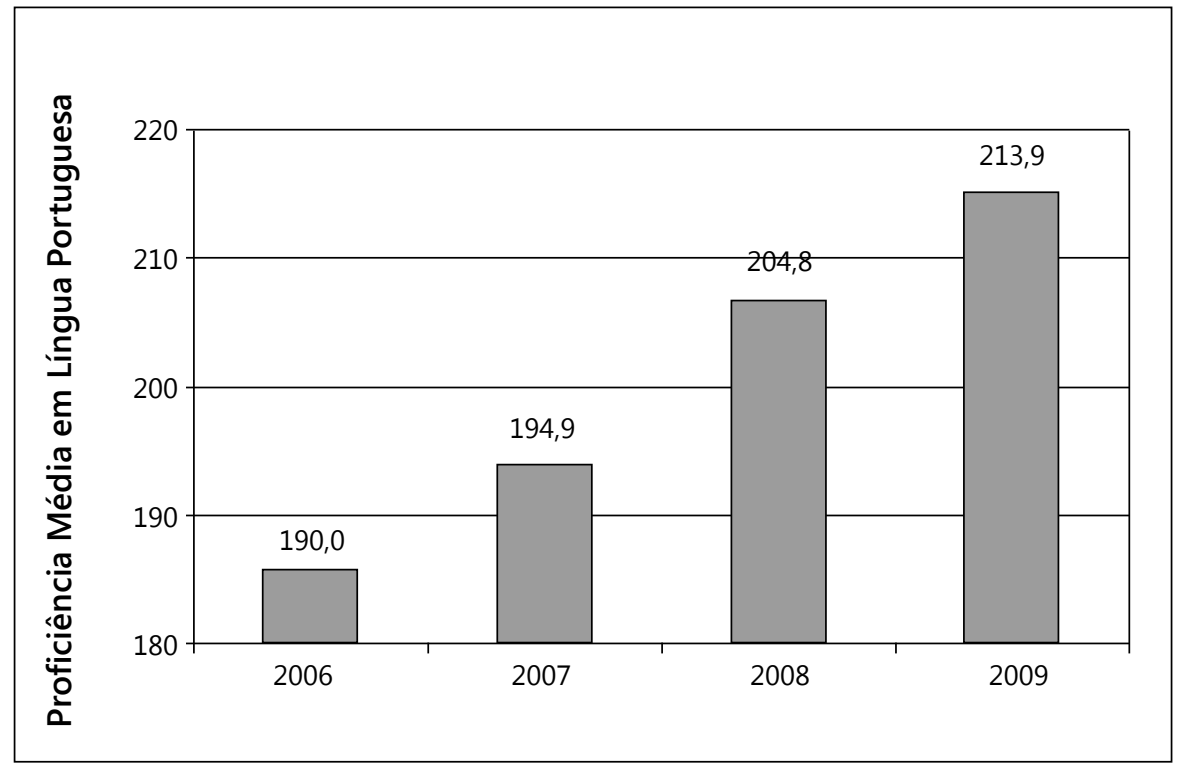

Fonte: SECRETARIA DE ESTADO DE EDUCAÇÃO DE MINAS GERAIS (2010). 
Gráfico 3 - Proficiência dos anos 2006 a 2009 em Matemática do $9^{\circ}$ ano da Rede Estadual

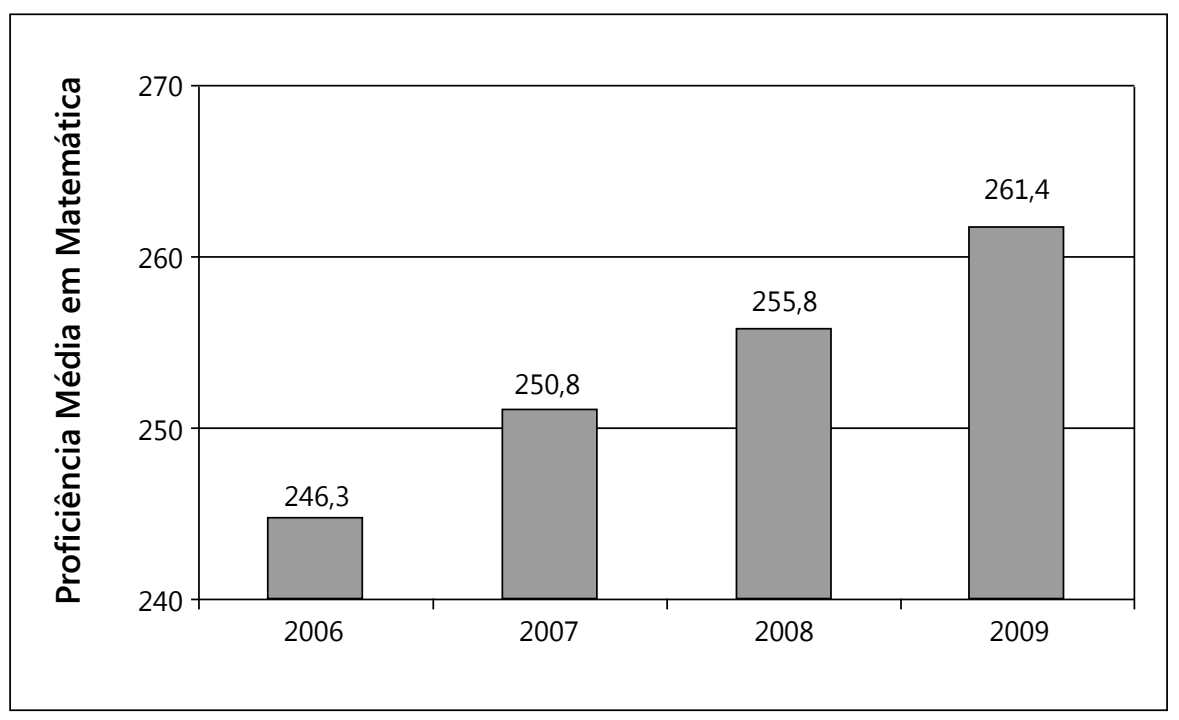

Fonte: SECRETARIA DE ESTADO DE EDUCAÇÃO DE MINAS GERAIS (2010).

Gráfico 4 - Proficiência dos anos 2006 a 2009 em Língua Portuguesa do 9ª ano da Rede Estadual

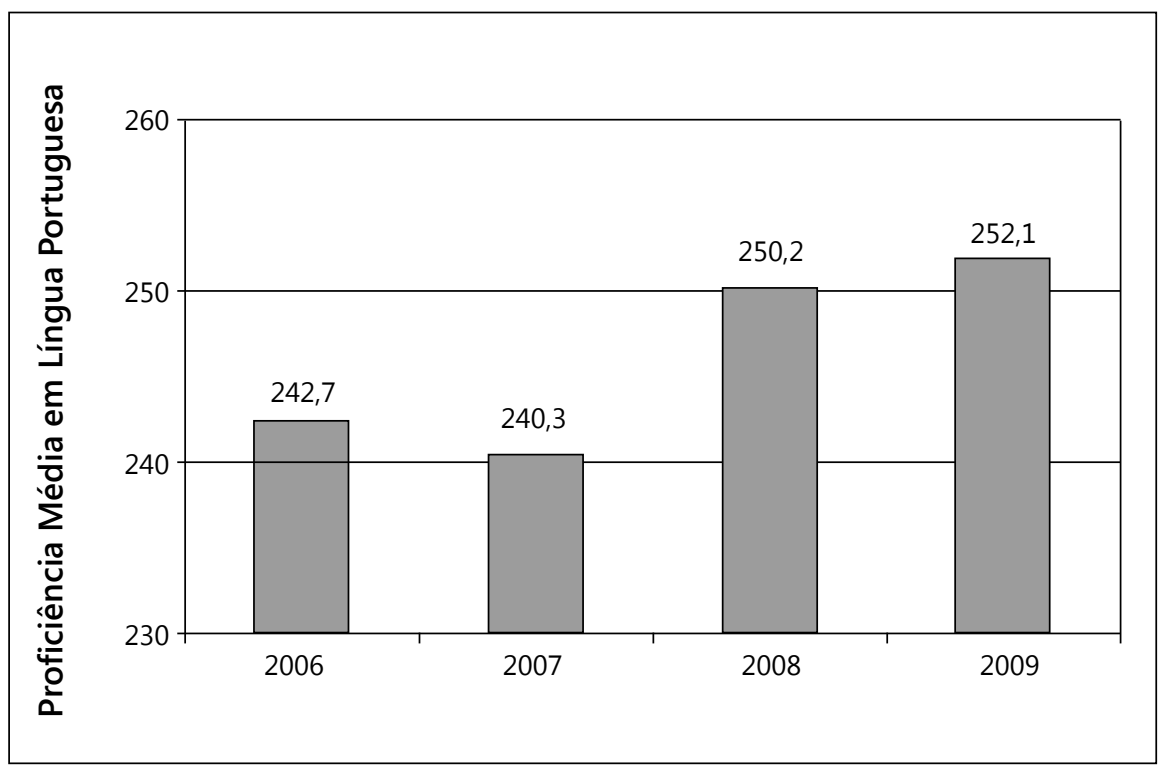

Fonte: SECRETARIA DE ESTADO DE EDUCAÇÃO DE MINAS GERAIS (2010). 
Os resultados observados nos gráficos mostram, claramente, uma evolução positiva dos níveis de proficiência dos alunos das escolas públicas mineiras ao longo dos anos 2006-2009. No entanto, são muitas as políticas públicas educacionais de iniciativa da SEE voltadas para o Ensino Fundamental neste período e é, portanto, impossível, num primeiro momento, atribuir a todos os projetos ou a um, em particular, a responsabilidade pelos resultados observados.

Nesse sentido, analisar o efeito do Projeto Escola de Tempo Integral no desempenho acadêmico do aluno requer técnicas estatísticas aprimoradas, tendo em vista que a maior parte das escolas, tanto as que aderiram ao projeto quanto as que não aderiram, tem apresentado crescimento nos níveis de proficiências cognitivas de seus alunos em Minas Gerais.

Estudos experimentais, em geral, são mais eficazes para avaliação dos efeitos de um determinado projeto. No entanto, como envolvem processo de escolha aleatória (probabilística) de grupos de participantes e não participantes, geralmente, são pouco aplicados em avaliação de projetos educacionais. A alternativa a eles são os estudos observacionais, em que os efeitos de um determinado projeto são analisados comparando-se os resultados observados para o grupo de participantes vis a vis os resultados de um grupo de não participantes do projeto, controlando-se, possivelmente, todos os demais fatores que poderiam interferir nesses resultados.

Nesse sentido, é preciso tentar avaliar se o crescimento observado para as proficiências cognitivas dos alunos das escolas que aderiram ao Projeto Escola de Tempo Integral foi maior do que o observado para as escolas que não aderiram. Por outro lado, como há diferenças substanciais nos perfis dos alunos nas diferentes escolas, como por exemplo, diferenças nas condições socioeconômicas dos alunos, é preciso também que a eficácia do projeto seja testada, controlando-se da melhor maneira possível essas diferenças.

Pelo exposto acima, a eficácia do Projeto Escola de Tempo Integral na dimensão das habilidades cognitivas dos alunos, refletida nos resultados do PROEB do $5^{\circ}$ ano do Ensino Fundamental, foi testada por meio de duas diferentes análises. $\mathrm{Na}$ primeira delas, foram construídos dois Modelos Lineares Hierárquicos ${ }^{2}-$ um para a disciplina de Língua Portuguesa e outro para a disciplina de Matemática

2 Modelo Estatístico adequado aos dados educacionais pois consideram o agrupamento dos alunos em escolas, tendo em vista que os modelos tradicionais de regressão consideram os casos como independentes. Ver Bryk \& Raudenbush (1992). 
- utilizando-se como variável dependente a proficiência individual dos alunos da Rede Estadual de Minas Gerais que cursavam o $5^{\circ}$ ano em 2009³ . Na construção desses modelos, e pelo exposto acima, foi necessário utilizar três variáveis independentes. Duas delas de controle: Proficiência no $5^{\circ}$ ano do Ensino Fundamental da escola no ano de 2006 (em Língua Portuguesa ou Matemática conforme a variável dependente utilizada); Condição socioeconômica do aluno ${ }^{4}$ (ISE aluno). E a terceira, a adesão (1) ou não (0) da escola ao Projeto Escola Tempo Integral $^{5}$ (TI). A variável dependente nos modelos é a proficiência do aluno em 2009 no $5^{\circ}$ ano do Ensino Fundamental. Uma associação entre a proficiência em $2009 \mathrm{e}$ a adesão da escola ao Projeto, tendo-se controlado a condição socioeconômica do aluno e a proficiência em 2006, é uma evidência de que o Projeto Escola de Tempo Integral pode estar tendo impacto sobre os resultados dos alunos participantes.

Uma restrição na análise realizada por meio dos modelos hierárquicos é que a participação no Projeto Escola de Tempo Integral não é possível de ser verificada em relação a cada aluno na escola, pois não há cadastros disponíveis para isso. Apenas se tem disponível a informação de que a escola participou ou não do programa. Portanto, o efeito sobre a proficiência do aluno é capturado de forma muito indireta e conservadora, pois, assim está-se admitindo que o projeto afeta todos os alunos da escola e não apenas os alunos participantes. De fato, essa hipótese se refletirá nos resultados encontrados e que serão apresentados na próxima seção.

Não sendo possível observar o efeito do programa diretamente sobre a evolução das proficiências de cada aluno participante, procurou-se avaliar também o efeito do programa sobre a evolução das proficiências médias do $5^{\circ}$ ano do Ensino Fundamental das escolas - novamente, salientando que nem todos os alunos das escolas de tratamento participaram do programa. Para isso, numa segunda análise, as escolas foram pareadas utilizando-se a técnica baseada em "escores de propensão" (GUO; FRASER, 2010). Isto é, cada escola, no conjunto daquelas que aderiram ao Projeto Escola de Tempo Integral, foi pareada a uma escola no conjunto daquelas que não aderiram ${ }^{6}$. Esta metodologia utiliza comparações entre grupos similares

3 Foram utilizados os dados do PROEB/2006/2009 - Língua Portuguesa e Matemática, pois estas bases concentram as informações mais recentes e disponíveis para análises da SEE/MG.

4 Construída por meio de perguntas que medem a posse de bens (culturais ou itens de conforto), além de considerar se a família recebe o benefício Bolsa Família, dado retirado do questionário do aluno no PROEB/2009 disponibilizado pela SEE/MG.

5 Relação das escolas que aderiram ao projeto até o ano de 2009, fornecida pela SEE/MG.

6 Para o cálculo dos escores de propensão, foram utilizados modelos de logísticos de regressão. O pareamento utilizou o critério do escore de propensão mais próximo, com limites máximos tolerados para suas diferenças. Ver Guo \& Fraser, 2010. 
entre si, segundo um conjunto de variáveis consideradas importantes para o controle. No caso, foram consideradas as seguintes variáveis de pareamento: o número de alunos avaliados na escola, a condição socioeconômica média dos alunos, a defasagem idade/série, média e o percentual de alunos do gênero masculino. Finalmente, a evolução das médias dos dois grupos foi comparada.

\section{Resultados da análise da eficácia do Projeto Escola de Tempo Integral: dimensão da evolução da proficiência cognitiva}

\section{Análise por modelos lineares hierárquicos}

Os Modelos Lineares Hierárquicos construídos e apresentados nas Tabelas 1 e 2 utilizaram, então, como variável dependente, a Proficiência do aluno em 2009, avaliando-se o efeito sobre ela da participação ou não da escola no Projeto de Tempo Integral, controlando-se os resultados pela média das proficiências dos alunos em 2006, das escolas e o ISE do aluno.

Tabela 1 - Modelo para Proficiência em Língua Portuguesa

\begin{tabular}{lll}
\hline Variável & Coeficiente & p-valor \\
\hline Intercepto & 114,61 & $<0,001$ \\
Proficiência média em LP em 2006 (escola) & 0,51 & $<0,001$ \\
Participação no Tempo Integral (escola) & 18,74 & 0,014 \\
Tempo Integral x Proficiência em LP em 2006 & $-0,10$ & 0,016 \\
ISE (aluno) & 5,73 & $<0,001$ \\
\hline
\end{tabular}

Fonte: os autores (2013).

Os resultados, apresentados na Tabela 1, indicam um efeito direto e positivo do projeto (coeficiente 18,74, significativo ao nível de 1,4\%), no entanto, apontam também um efeito menos expressivo nas escolas com média de proficiências mais alta. Isso significa que o efeito só é significativo para escolas com médias mais baixas de proficiência. Isso pode ser observado analisando-se conjuntamente o efeito direto do projeto e o efeito da interação entre o efeito do projeto e a proficiência média em 2006. Observe que o efeito 
do projeto no modelo pode ser analisado por meio da relação: $(18,74-0,10$ x Proficiência média em LP em 2006) x Participação da escola no TI. Isso quer dizer que o efeito só se mostra expressivo naquelas escolas em que a proficiência média dos alunos é mais baixa. Esse resultado é absolutamente coerente, pois o projeto é destinado aos alunos de mais baixa proficiência. Escolas com médias mais elevadas, provavelmente, terão pouco alunos no projeto comparativamente ao número total de alunos da escola.

De outra forma, também pela análise do modelo apresentado na Tabela 1, pode-se perceber que, ao se controlar o ISE, os resultados em Língua Portuguesa dos alunos que estudavam em instituições que não aderiram ao Projeto Escola de Tempo Integral, apresentaram em 2009 a proficiência em torno de 115 pontos, acrescidos de $51 \%$ da proficiência média da escola no ano de 2006. Enquanto os alunos que estudavam em escolas que aderiram ao projeto apresentaram em 2009 a proficiência em torno de 133 pontos, acrescidos de $41 \%$ da proficiência média da escola no ano de 2006 . Ou seja, controlado o nível socioeconômico, as proficiências dos alunos que estudavam nas escolas que participavam do projeto dependiam menos dos resultados médios das escolas em 2006 - nesse caso deve-se considerar para o cálculo o efeito do termo de interação (Tempo Integral x Proficiência em LP em 2006) presente no modelo.

Tabela 2 - Modelo para Proficiência em Matemática

\begin{tabular}{lll}
\hline Variável & Coeficiente & p-valor \\
\hline Intercepto & 115,49 & $<0,001$ \\
Proficiência média em MT em 2006 (escola) & 0,56 & $<0,001$ \\
Tempo Integral (escola) & 17,83 & $<0,038$ \\
Tempo Integral x Proficiência em MT em 2006 & $-0,09$ & $<0,046$ \\
ISE (aluno) & 6,75 & $<0,001$ \\
\hline
\end{tabular}

Fonte: os autores (2013).

Os resultados de Matemática são muito similares e as conclusões praticamente as mesmas. Assim, da mesma forma que em língua portuguesa, pelos resultados do modelo apresentados na Tabela 2, pode-se perceber que, ao se controlar o ISE, as proficiências dos alunos que estudavam em instituições que não aderiram 
ao Projeto Escola de Tempo Integral, estavam em 2009 em torno de 116 pontos acrescidos de 56\% da proficiência média da escola no ano de 2006. Enquanto os alunos que estudavam em escolas que aderiram ao projeto apresentavam suas proficiências em torno de 133 pontos, acrescidos de $47 \%$ da proficiência média da escola no ano de 2006.

Os resultados gerais dos modelos indicam que a adesão da escola ao projeto tem um efeito pequeno e positivo, porém significativo, sobre a proficiência dos alunos das escolas com alunos de mais baixa proficiência cognitiva (ver a ilustração apresentada nos gráficos 5 e 6, que ilustram o efeito do programa capturado pelo modelo). Os resultados condizem com os objetivos do modelo de Tempo Integral implantado, primordialmente voltado para o atendimento daqueles alunos com alta vulnerabilidade social e os de baixa proficiência, não atingindo a todos os alunos da escola.

Assim, novamente, observa-se que os modelos hierárquicos capturam apenas parcialmente o efeito do programa. Principalmente por atribuir a todos os alunos da escola que tenha aderido ao programa TI um possível efeito do programa, mesmo quando o discente não participa diretamente do programa. Esse é, provavelmente, o motivo de se observar a interação encontrada e o efeito apenas sobre os alunos das escolas de médias de proficiências mais baixas.

Gráfico 5 - Comparação das Proficiências nos anos 2006 e 2009 em Língua Portuguesa

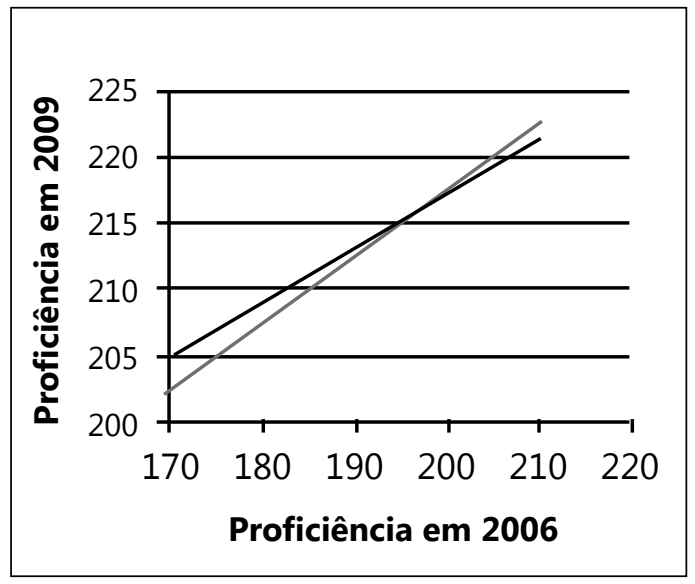

Fonte: RELATÓRIO FINAL DO PROJETO TEMPO (2010). 
Gráfico 6 - Comparação das Proficiências nos anos 2006 e 2009 em Matemática

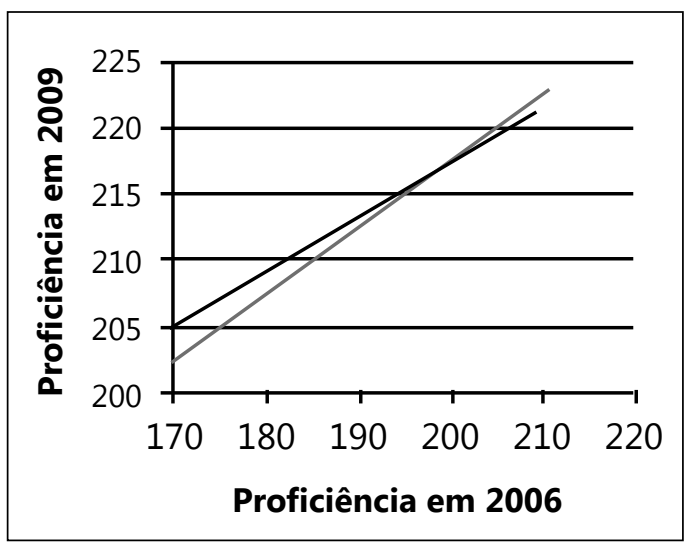

Fonte: RELATÓRIO FINAL DO PROJETO TEMPO (2010).

\section{Escolas sem TI Escolas com TI}

\section{Análise por escores de propensão}

O ideal seria verificar o efeito do programa diretamente sobre a evolução das proficiências dos alunos que de fato participam do programa ao longo do tempo e compará-las à evolução observada para um grupo controle de alunos, que tenha sido submetido a condições escolares similares e de mesmas características sociodemográficas, mas que não participaram do programa. Infelizmente esse estudo ainda não foi previsto. Pode-se conjecturar, então, que os resultados aqui são conservadores, e o efeito do projeto sobre os alunos que, de fato, participam do Projeto de Tempo Integral é bem mais expressivo do que o que está sendo capturado pelos modelos acima. Não sendo possível observar o efeito do programa diretamente sobre a evolução das proficiências dos alunos, procurou-se avaliar o efeito do programa sobre as proficiências médias das escolas. Para isso utilizou-se a técnica de pareamento por escores de propensão. Esta metodologia compara a evolução das médias de proficiências das escolas participantes do projeto com um grupo de escolas não participantes, mas que são muito similares entre si.

São apresentados nos gráficos 7 e 8 as médias de proficiências dessas escolas (pareadas) participantes e não participantes no Projeto Escola de Tempo Integral. 
Gráfico 7 - Proficiência Geral em Matemática

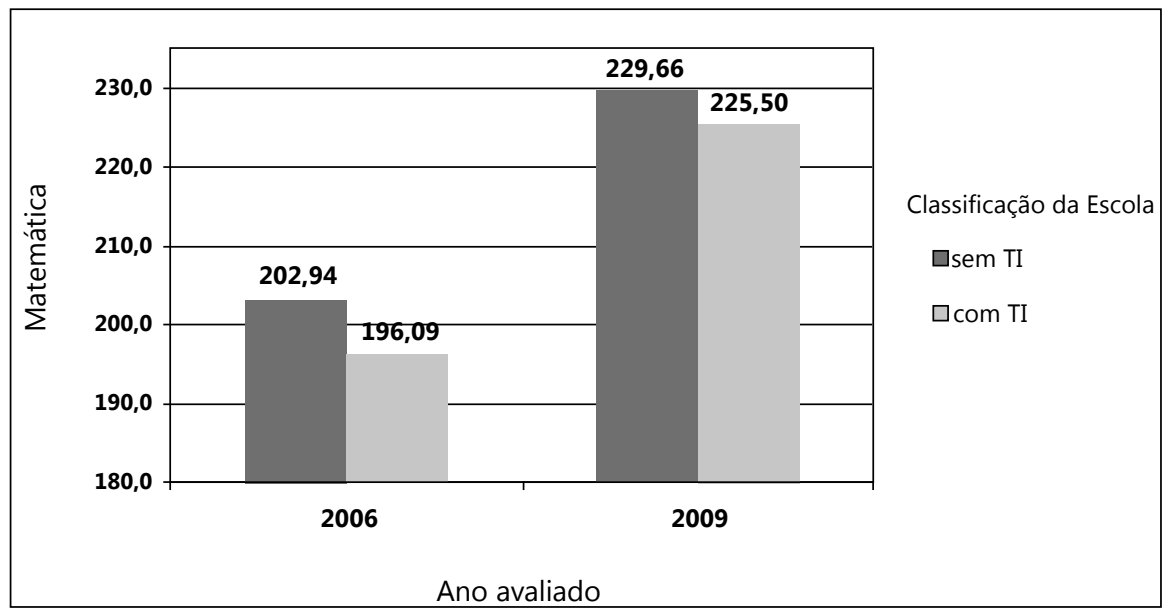

Fonte: RELATÓRIO FINAL DO PROJETO TEMPO INTEGRAL, (2010).

Gráfico 8 - Proficiência Geral em Língua Portuguesa

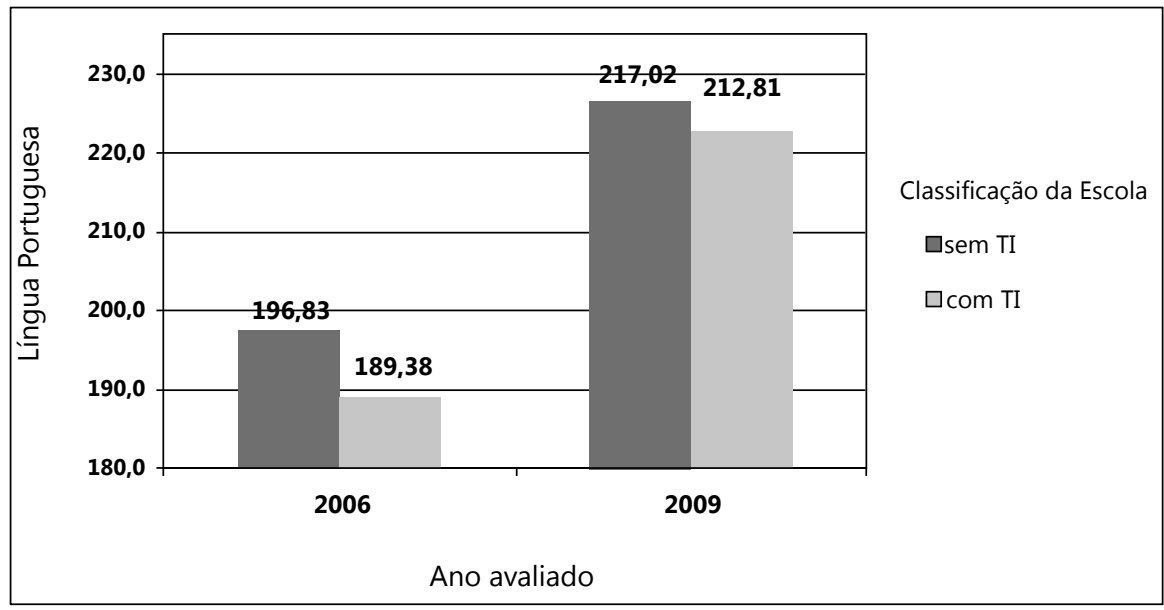

Fonte: RELATÓRIO FINAL DO PROJETO TEMPO INTEGRAL (2010).

Observa-se que a média de proficiências, em 2006, dos alunos das escolas que aderiram ao TI, em algum momento entre 2007 e 2009, era de 196 em matemática. Já a média de proficiência dos alunos das escolas que não aderiram era de 202,9, uma diferença de 6,9 pontos. Em 2009, a média das proficiências em matemática dos alunos das escolas que aderiram ao Projeto Escola de Tempo Integral era de 
225,5 e a dos alunos das escolas que não aderiram era de 229,6, uma diferença de 4,1 pontos. Tem-se, então, uma queda na diferença entre as médias dos alunos das escolas que aderiram ao Projeto Escola de Tempo Integral e dos alunos das escolas que não aderiram ao projeto, de 6,9 pontos para 4,1 pontos. Esse efeito, estatisticamente significativo, pode ser atribuído ao projeto, embora seja muito pequeno. Esse resultado corrobora o resultado encontrado na primeira análise.

Novamente é preciso cautela com os resultados pois, da mesma forma que na análise anterior, o efeito do projeto está sendo capturado de forma indireta e conservadora. Primeiro porque, como tem sido enfatizado, nem todos os alunos participam do projeto; segundo porque as escolas não, necessariamente, aderiram ao projeto ao mesmo tempo, e pode haver uma interferência do tempo de adesão nos resultados - presume-se que o efeito do projeto seja mais expressivo nas escolas que aderiram há mais tempo. De qualquer forma, essas duas restrições conduzem a resultados mais conservadores, no sentido de que, se pudessem ser controlados esses efeitos, a importância do projeto ficaria mais evidente. Assim, os resultados de ambas as análises indicam que há evidências de que o Projeto Escola de Tempo Integral apresenta eficácia no aspecto da melhoria do desempenho escolar medido através dos resultados de avaliações educacionais em larga escala. Ainda resta dúvida quanto à magnitude desse efeito, tendo em vista as dificuldades encontradas nos estudos.

\section{Conclusão}

Ambos os estudos realizados, que procuraram analisar a evolução das proficiências dos alunos das escolas estaduais mineiras que aderiram ou não ao Projeto Escola de Tempo Integral, evidenciam um efeito do projeto na evolução das médias de proficiências das escolas de forma consistente, porém pequena. No entanto, as mesmas análises evidenciam que escolas com menor média de proficiências no ano de início do projeto foram as mais beneficiadas, destacando, assim, uma eficiência alcançada, provavelmente, pela característica do projeto proposto que beneficia os alunos de baixa proficiência e, ou, os de maior vulnerabilidade social.

Percebe-se como necessária, como fundamental para aprofundar as análises, a realização de novos estudos pautados na identificação dos alunos participantes do projeto, assim como seus resultados nas avaliações do PROEB. Os estudos observacionais, baseados em modelos hierárquicos e em pareamento por escores 
de propensão, como os que aqui foram realizados, seriam muito mais eficazes nesse caso. Provavelmente, o efeito capturado do projeto seria mais expressivo, pois estariam sendo comparados os alunos que efetivamente dele participaram. Por outro lado, um estudo longitudinal, aleatorizado, de coorte, com grupo de tratamento e controle, seria ainda mais eficaz para mensurar os efeitos do projeto de Tempo Integral. Infelizmente, esses estudos, por muitos motivos, são difíceis de serem produzidos e, provavelmente, os estudos observacionais são mais factíveis.

Finalmente, sugere-se a extensão dos estudos aos alunos de outras séries, pois poderiam ser analisadas as diferenças de eficácia ao longo das etapas escolares, mas também, o efeito cumulativo do projeto ao longo dos ciclos escolares. Outros objetivos do projeto também poderiam ser avaliados. Por exemplo, haveria influência do projeto em variáveis não cognitivas, como as emocionais e sociais, por exemplo? Nesse caso, seria preciso medir essas variáveis de alguma forma, o que não é comum nos sistemas de avaliações em larga escala.

Os resultados encontrados neste trabalho são auspiciosos no sentido de que vale a pena investir nos estudos de eficácia dos diversos modelos de escola em tempo integral que estão começando a ser implantados no país e que, provavelmente, vão apresentar resultados no sentido de melhorar a qualidade da educação. Por outro lado, ele adverte de que é preciso investigar, metodicamente, a eficácia de cada modelo implantado, pois não está ainda claro qual será o ganho que um projeto de tal magnitude pode trazer para a qualidade da educação no país, vis a vis alternativas menos custosas ou outros modelos de ampliação da jornada escolar.

\section{Referências}

BRYK, A. S., RAUDENBUSH, S. W. Hierachical linear models: applications and data analysis methods. Newbury Park, Califórnia: Sage Publications, 1992.

CAVALIERE, Ana Maria. Escolas de tempo integral versus alunos em tempo integral. In: MAURÍCIO, Lúcia Velloso (Org.). Educação integral e tempo integral. Em Aberto, Brasília, DF, v. 22, n. 80, p. 51-64, abr. 2009.

COELHO, Lígia Martha C. da Costa. História da Educação Integral. Em Aberto, Brasília, DF, v. 22, n. 80, p. 83-96, abr. 2009. Disponível em: <http://emaberto.inep. gov.br/index.php/emaberto/article/viewFile/1472/1221>. Acesso em: 30 mar. 2012. 
GUO, S.; FRASER, M. Propensity score analysis: statistical methods and applications: SAGE, 2010. (Serie 11).

SECRETARIA ESTADUAL DE EDUCAÇÃO DE MINAS GERAIS. Escola de Tempo Integral. Belo Horizonte: SEE/MG, 2009.

SECRETARIA ESTADUAL DE EDUCAÇÃO DE MINAS GERAIS. Resultados do PROEB. SEE/MG [on line], 2010. Disponível em: < https://www.educacao. mg.gov.br/component/content/article/108/1648-resultados-do-proeb-2009mostram-que-os-alunos-mineiros-do-ensino-basico-estao-aprendendo-mais $>$. Acesso em: 13 dez. 2010.

RELATÓRIO FINAL DO PROJETO TEMPO INTEGRAL. Minas Gerais: SEE/ MG, 2010.

Recebido em: 16/06/2011

Aceito para publicação: 29/08/2013

\section{Full-time school: results from the project on the proficiency of elementary school students from the public schools in Minas Gerais Abstract}

This work evaluates the effects of the project 'Escola em Tempo Integral" (Fulltime school), developed by the government of Minas Gerais since 2007 at public schools, on the results of large scale evaluations of Math and Portuguese. The project is presenting positive results on the improvement of the proficiencies of the students who have a delay in learning process. The observational study was based on the results of students from about 1900 schools that acceded to the project between 2006 and 2009, using techniques based on propensity score and regression multilevel models.

Keywords: Elementary school. Evaluation of the Educational Policies. Full-time school. Multilevel Model. Propensity Score. 


\section{Escuela de Tiempo Completo: resultados del proyecto en el desempeño de los alumnos de Educación Básica de las escuelas públicas da la red estatal de Minas Gerais Resumen}

En este trabajo se evalúan los efectos del Proyecto Escuela de Tiempo Completo (en su original: Escola em Tempo Integral), desarrollado por el gobierno de Minas Gerais desde el año 2007 en las escuelas estatales, en los resultados de las evaluaciones en gran escala de Portugués y Matemáticas. En ese sentido, el proyecto demuestra resultados positivos al promover el desempeño de los alumnos con desfase de aprendizaje. El estudio observacional se basa en los resultados de los alumnos de cerca de 1900 escuelas que incorporaron el proyecto entre los años 2006 y 2009, utilizando técnicas basadas en el puntaje de propensión y en los modelos multiniveles de regresión.

Palabras-clave: Educación Básica. Evaluación de las Políticas Educacionales. Escuela de Tiempo Completo. Modelo Multinivel. Puntaje de Propensión. 